\title{
COLOUR EFFECTS EDUCATION THROUGH TECHNOLOGY: COLOUR-IN PROJECT
}

\author{
by \\ Anastasiia Semenenko \\ Bachelor of Management, Kyiv National Linguistic University, 2009 \\ Associate of Applied Science, Northern Virginia Community College, 2014
}

\begin{abstract}
A Major Research Project
presented to Ryerson University

in partial fulfilment of the

requirements for the degree of

Master of Digital Media

in the program of Digital Media.
\end{abstract}

Toronto, Ontario, Canada, 2017

(C) Anastasiia Semenenko, 2017 


\section{Author's Declaration}

I hereby declare that I am the sole author of this MRP. This is a true copy of the MRP, including any required final revisions.

I authorize Ryerson University to lend this MRP to other institutions or individuals for the purpose of scholarly research.

I further authorize Ryerson University to reproduce this MRP by photocopying or by other means, in total or in part, at the request of other institutions or individuals for the purpose of scholarly research.

I understand that my MRP may be made electronically available to the public.

Anastasiia Semenenko 


\title{
COLOUR EFFECTS EDUCATION THROUGH TECHNOLOGY:
}

\author{
COLOUR-IN PROJECT \\ Anastasiia Semenenko \\ Master of Digital Media, 2017 \\ Yeates School of Graduate Studies \\ Ryerson University
}

\begin{abstract}
This paper represents the research and analysis of the psychological impacts of colour, as well as discusses the importance of the awareness of such effects. The theoretical rationale provides context and details plan for a proposed digital tool - a not-for-profit educational mobile iOS application Colour-In - that detects and measures colours from a supplied image, analyzes, and provides information about the psychological influence and significance of those colours. The overall goal of the project is to contribute to the education of colour effects and improve the learning experience by integrating digital technologies into the educational process in various academic and professional practices.
\end{abstract}

Keywords: colour psychology, colour effects, colour education, colour therapy, colour measurement technology, mobile application 


\section{Acknowledgements}

This major research project would not have been possible without the excellent guidance of my supervisor Dr. Richard Adams. Thank you for your valuable support and helpful feedback throughout the entire course of the project.

I would also like to acknowledge Michael Carter, Alex Ferworn, and Sonya Taccone for their encouragement and assistance, and my colleagues in the MDM Cohort 2016-2017 for the great collaboration, inspiration, and friendship.

Finally, no words are enough to thank my parents Tetyana and Anatolii Semenenko and my "second parents" Kathleen and Robert Rawls for their endless support. Thank you for always being there for me. 


\section{Table of Contents}

Author's Declaration............................................................. ii

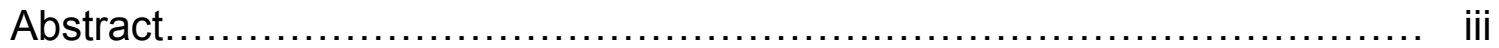

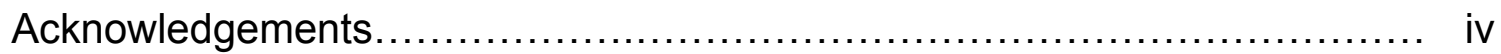

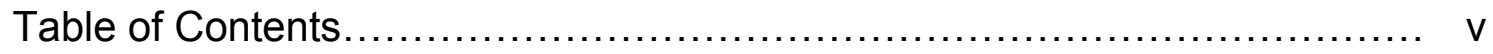

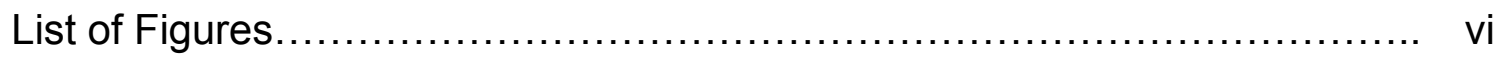

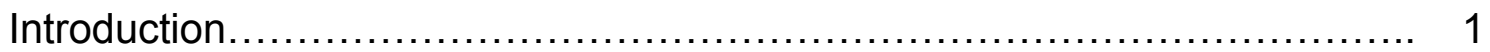

The Importance of Knowledge of the Impact of Colour....................... 2

Project Description, Process, and Expected Final Product................... 5

Further Steps, Contribution, and Limitations............................. 8

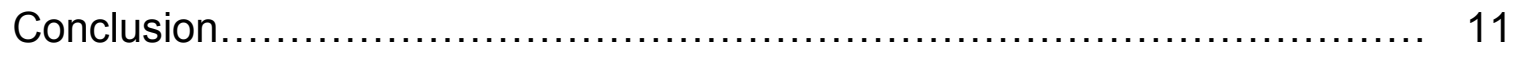

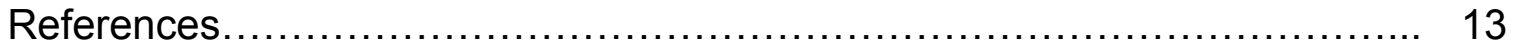




\section{List of Figures}

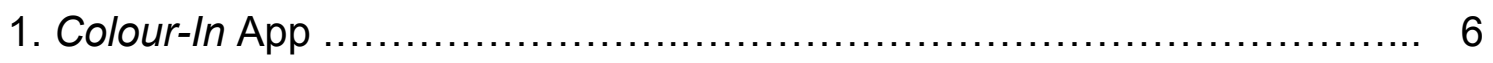

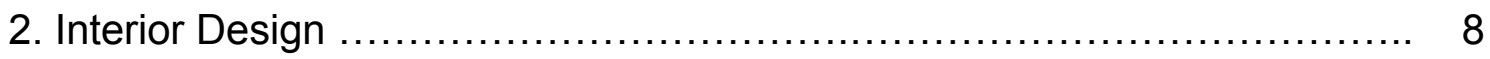

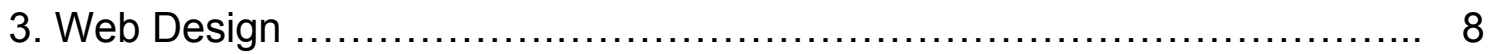

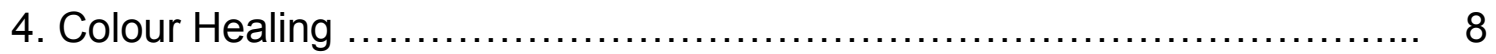




\section{Colour Effects Education Through Technology: Colour-In Project}

\section{Introduction}

Colour is one of the most significant visual experiences for human beings in all facets of life. The studies have shown that the colour of the surroundings may influence a person's mental, physical, and emotional state; and furthermore, can affect people psychologically and therapeutically (Birren, 2013).

The advancements in technology can create opportunities to merge traditional theoretical framework with modern digital tools. Therefore, the goal of this project is to create a design solution allowing technology to play a meaningful role in the development of the knowledge of potential colour effects using primary principles of colour theory and studies of colour psychology.

Moreover, based on the theoretical foundations, the intention of the project is to introduce the idea and take the first step in the prototyping process of the proposed digital tool - a mobile application Colour-In - that could potentially benefit future research in the areas of colour psychology, therapy, and colour measurement technologies. It could also support the promotion of the use of digital device applications for educational purposes, discipline-related practices, and thereby, make a contribution to communities (Gutierrez, 2014).

The main learning objectives of the project are to explore the way to integrate technologies into the improvement of the impact of colours learning experience and create an efficient user interface that would leverage evolving mobile device capabilities. 


\section{The Importance of Knowledge of the Impact of Colour}

Before introducing the idea of the digital tool, it is crucial to outline the reasons the awareness of the influence of colours is substantial. There has been a considerable amount of previous academic research done in the field of colour. However, most of the past studies were primarily focused on a general explanation of the foundations of various colour theories, for instance, Goethe's Theory of Colours, Runge's study The Colour Sphere, Munsell's colour system Colour Notation, Newton's Colour Circle, Mayer's Colour Triangle, etc., and the science behind colour with often lacking information on psychological aspects, aesthetics, and meanings of colours. However, colour deserves much more attention as it is the most powerful stimulus for the brain and the entire nervous system; and therefore, it plays a considerable role in influencing human's physiological, mental, and emotional condition (Karr, 2013).

Also, colour is a powerful feature as people interpret its cues on an unconscious level: $62 \%$ - $90 \%$ of the behavioural responses are based on the use of colour, which makes it a powerful psychological trigger (Gutierrez, 2014). As an example, it can change user experience by altering the perception and setting the mood. So it's important to always link general meanings and associations to specific colours to determine the emotion that selected colour schemes could evoke. For instance, use of red, orange, and yellow could add more energy and stimulation, whereas green, blue, and violet would form a more relaxed flow (Gutierrez, 2014). 
The proper use of colours can be very effective, for example, in educational settings. It can enhance learning experience since it operates as a powerful information channel to the human cognitive system. Moreover, it has been found to play a significant role in enhancing memorization, recall, recognition, and attention (Dzulkifli, 2013). The Institute for Colour Research (now called Colour Matters) verified that colour can improve learning from 55 to $78 \%$ as well as comprehension by as much as $73 \%$ (Gutierrez, 2014). Consequently, one of the most effective ways to boost students' learning engagement is to integrate the proper use of colour into the instructional materials and technology.

Also, when it comes to practical aspects, the understanding of the basics of the science behind colour and its psychological influence on the human senses is crucial in its appliance in visual design in any field (Hemani, n.d.). As colour affects user experience and the effectiveness of the design, it certainly becomes the bottom-line in web design, product design, urban design, interiors, fashion, packaging, and of course, marketing and branding. For instance, according to Dzulkifli (2013), colour can increase brand recognition by up to $80 \%$; and most advertisements use colour as the major principle in "influencing people's attention and attitude towards the product, and pressuring decisionmaking" (para. 3).

In addition to using colour as one of the best methods to "utilize the power of visual tools", the findings from the studies on the influence of colours on body 
and mind can also provide a meaningful insight on education in relation to therapeutic and healing effects (Gutierrez, 2014). A colour therapy, or chromotherapy, can be used medically as a non-invasive, holistic, and powerful treatment, as colour has a very strong radiating effect on the whole body. Ancient cultures, including the Chinese, Indians, and Egyptians, practiced chromotherapy to cure; and even nowadays, it is still utilized as a healing alternative treatment (Cherry, 2017).

Therapists believe that applying colour of the corresponding vibrational energy from the surroundings could heal disorders of each organ and the entire body system (Birren, 2013). Thereby, colour impacts could be applied in interior design for healing purposes and obtain the most effective therapeutic environmental solutions, where the effects of visual colour stimulation could affect patients' rehabilitation pace. For instance, it has been found that patients surrounded in a more saturated-colour room setting needed less painkillers and generally recovered $75 \%$ of a day faster (Hill, 2008). Also, it has been suggested that red surroundings could raise blood pressure, respiration, heart rate, and stimulate senses and had a greater capacity for arousal than blue; or "soothing green" work environment experience could reduce stomach aches (Cherry, 2017). Therefore, designers should value and take into account the discoveries for creating healing environmental conditions and give the use of colour as a visual design element more consideration (Mahnke, 1996). 
Chromotherapy is also sometimes associated with a colour light therapy, as a broad range of academic studies highlights the effects of coloured lightwaves with regard to human response (Cherry, 2017). For example, some wavelengths of light may improve cognitive performance; or different coloured lenses may assist with reading difficulties such as dyslexia (O'Connor, 2011). Also, it was reported that the reading speed of autistic patients, who were using a coloured overlay when reading, was increased up to 35\% (Ludlow, 2009). Moreover, there is a more non-traditional approach to colour light healing - a colour-chakra theory - that suggests that colour is connected to each of the seven chakras of the body and associated with its functions and dysfunctions within each chakra area, and therefore, could be used as a treatment tool (O'Connor, 2011). For example, green is used to treat malaria, back problems, cancer, nervous disorders, ulcers, etc. (Kopacz, 2003).

As we can see, the use of colour in visualization could be the most effective and easiest to utilise tool in psychological influence and possible healing (Wright, n.d.). Therefore, the communities must adopt a new attitude toward the research and education in the field of colour influence and its integration into modern technologies.

\section{Project Description, Process, and Expected Final Product}

The examination of the existing theoretical studies has established the base for the explanation of the purpose of the project and design hypothesis for the proposed Colour-In application. 
The proposed digital tool - Colour-In - is a not-for-profit educational mobile application (Figure 1) that detects colours of images, analyzes and summarizes information, displays received data, and provides colour psychological explanations and recommendations accordingly. The target audience includes psychologists, physicians, designers, colourists, teachers, or anyone using colour in work and life.

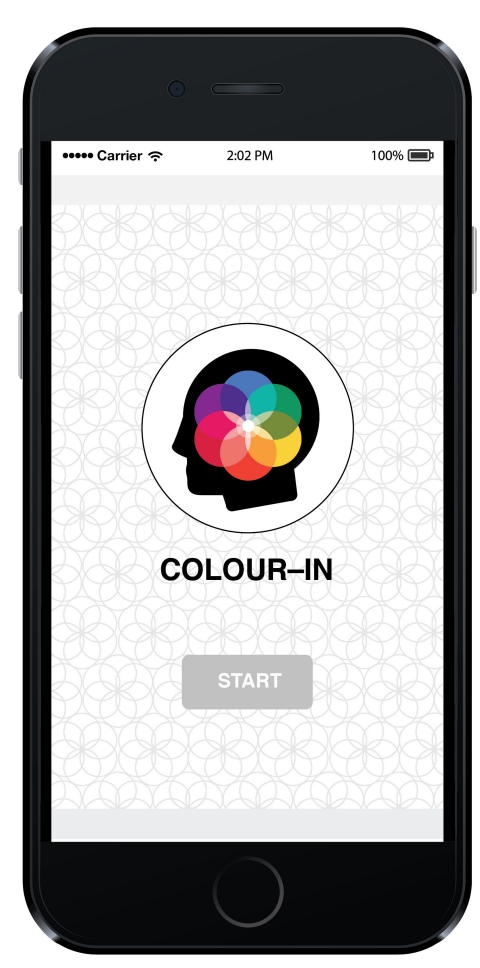

Figure 1. Colour-In App
So how will the Colour-In application work? The main function of the application will be based on colour measurement using colour detection sensors. A user can import a previously saved image or take one with the mobile device's camera for the colour recognition process. It will require developing and applying various software imageprocessing algorithms that facilitate the operation of detecting colours by processing pixel values and producing the colour in HSL colour space (converting RGB images into HSL). The average value of the colour (the $\mathrm{H}$ component) will be compared with a predefined reference chart of colours. If the captured image is too bright or too dark, which is determined based upon the saturation and intensity elements, a special warning message will be displayed (Arati, 2015).

By clicking on a specific point on the image using a Colour Picker tool, a user will be able to change the active spotted colour. Besides having an option of 
defining any colour on the image and receiving information about it, including a number and name identification (according to the selected colour mode - RGB, CMYK, LAB, etc. which could be easily altered), the application will also determine a dominant colour and palette that will list the top eight colours in order of predominance. Thereafter, a user will be able to click on any detected colour (picked, dominant, or one from the palette) to receive a more detailed analysis of the selected colour with its approximate percentage.

Finally, the analysis will utilize the main purpose of the proposed application - display information about the common psychological traits of the examined colour. Moreover, it will give suggestions for the use of colour according to the available theoretical colour studies and practices. The context of the presented information will depend on the subject of the image. Consequently, the meaning of the analyzed colour could be manually switched according to the theme of the image: interior design, web design, landscape or urban design, colour therapy and healing, just a general meaning of the colour, etc.

The project aims to take the first step in the prototyping process for the proposed Colour-In application development. The provided design mockups of the tool with 3 examples of use case scenarios - interior design, web design, and colour healing themes (Figures 2-4) - serve to better illustrate the idea of the digital tool, articulate all the desired functionality, and outline how exactly the application fulfills the purpose of the project. 


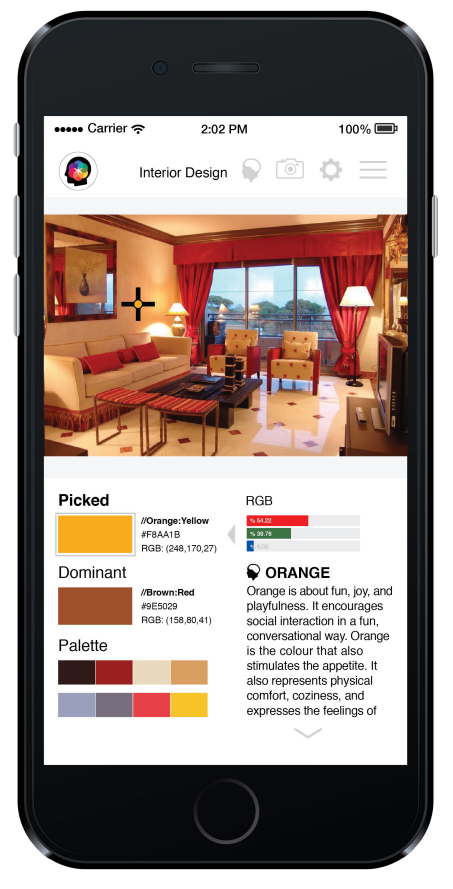

Figure 2. Interior Design

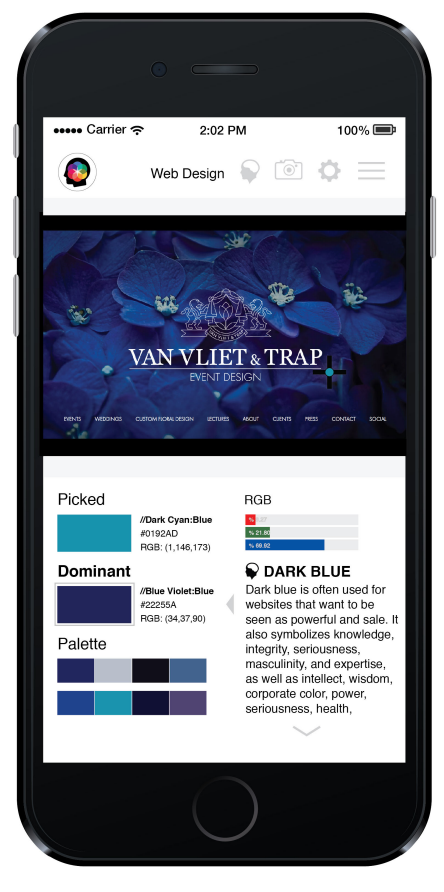

Figure 3. Web Design

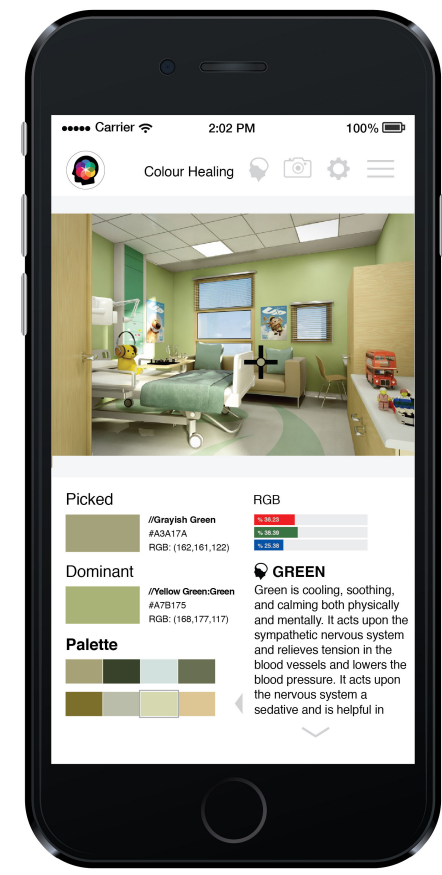

Figure 4. Colour Healing

The mockups also demonstrate a tentative user interface design, as well as how the application analyzes the colours from the images and explains the effects the analyzed colours can produce. However, this is only the first step of the process of building the proposed application; the provided prototypes will then be amplified to a user testing process to determine the level of effectiveness of the proposed digital tool.

\section{Further Steps, Contribution, and Limitations}

To make the proposed digital tool a completed product and prove the value of the research and the concept, the next step of the prototyping process will require user testing and feedback. It will contribute to the further defining of 
the user goals and the development process of the design by finalizing user interface and the most efficient way of presenting information. Also, it will specify the requirements for the Colour-In application and improve its features. In other words, the next stage would be to test and evaluate the accuracy and usability of the tool, as well as to determine its effectiveness and address possible challenges. Also, presenting the idea to the industry professionals and testing the project prototype by intended target audience will identify its potential, further strategy, and a business plan development.

When it comes to the appropriateness and contribution of the project, it is defined by the its goal, which is to contribute to the field of colour education and improve its learning experience by integrating digital technologies in various professional practices. For example, the study of biological consequences of responses to colour effects could be a valuable applied tool in health management (Kopacz, 2003). Many daily decisions are usually made depending on colour interpretation. However, "a number of colour's mysteries and ambivalences remain active and unresolved in Western culture" (Kane, 2014, p. 27). As many people underestimate or are unaware of the potentially positive or negative psychological effects of colour, the proposed application will allow to promote the colour effects knowledge among population and hereby boost wellbeing with a proper use of colour. In other words, with the overall development of colour psychological effects knowledge, many people will benefit from the project, both directly and indirectly. 
Provided above design mockups demonstrate where the proposed digital tool could be valuable and how it would address the intended target audience. Therefore, information about the influence of colour learned with the help of the proposed application could be used medically for healing purposes to improve mental and physical state, educationally to enhance learning experience and memorization, or generally enhance users' knowledge about the colour effects.

During the process of the project research, some possible limitations and challenges have arisen. Many people still remain rather sceptical about the studies of psychological effects of colour and concerned about its subjective meanings (Karr, 2013). For example, it is believed that visual responses to colour could also diversify across cultural, personal, or societal differences (Kane, 2014); or the findings are based mostly on a limited range of colour samples (O'Connor, 2011). According to Elliot (2015), "theory in this area remains at a nascent level of development, and the weaknesses may be identified" (para. 9). As the result, the potential users may find the provided with the proposed application information about colour effects rather inaccurate and irrelevant, and it might affect the further process and development of the idea.

Such controversy in the research findings may require an adaptation and finding an alternative design solution by adding extra features to the application. The possible solution could include a geographic location of the intended project or having an option of choosing the cultural aspect, or simply adding more interpretations to the content of the displayed psychological information. Certainly, adding extra features will also require further user feedback. 
Nevertheless, information regarding psychological effects of colours, provided by the Colour-In digital tool, will not claim to prove or argue any scientific data regarding the influence of colour. The displayed information will be based on the existing research and evidence, and the proposed application will be aimed to serve only as an assistive digital tool.

\section{Conclusion}

Throughout the research and development of the content and methodology, there were many learning experiences that helped to achieve the goals of the project and support the outline for the proposed digital tool - ColourIn. They were based on the theoretical background that examined the benefits of the awareness of the psychological properties of colour. Embracing this information could assist people in understanding the factors that must be reckoned when creating beneficial and healthy surroundings (Mahnke, 1996). Therefore, the review of the theoretical framework was used to explain the main purpose of the proposed digital tool.

Also, the project was implemented using an interdisciplinary approach, which intersected main areas of digital media - technology, design, and business. Also, it covered various aspects of research and project development that were related to the digital media field, including critical thinking, creative and design processes, prototyping, user experience, mobile application development plan, and examination of colour recognition tools. 
Generally, the project succeeded in achieving all previously defined objectives. This reflection paper and design mockups have not only built a strong basis for the next steps in the development of the project, but also potentially opened up a direction for the further research in the field of the impact of colour and its integration into the modern technology. 


\section{References}

Arati, K., \& Sayali J. (2015). Object recognition in mobile phone application for visually impaired users. IOSR Journal of Computer Engineering, 17, 30-33. Retrieved from http://www.iosrjournals.org/iosr-jce/papers/Vol17issue1/Version-3/G017133033.pdf

Birren, F. (2013). Color psychology and color therapy: A factual study of the influence of color on human life. Eastford, CT: Martino Fine Books.

Cherry, K. (2017). Colour psychology: Does it affect how you feel? Retrieved from https://www.verywell.com/color-psychology-2795824

Dzulkifli, M. A., \& Mustafar, M. F. (2013). The influence of colour on memory performance: A review. The Malaysian Journal of Medical Sciences : MJMS, 20(2), 3-9. Retrieved from https://www.ncbi.nlm.nih.gov/pmc/articles/PMC3743993/

Elliot, A. J. (2015). Color and psychological functioning: A review of theoretical and empirical work. Front. Psychol, 6, 368. doi: 10.3389/fpsyg.2015.00368

Gutierrez, K. (2014). 6 ways colour psychology can be used to design effective eLearning. Retrieved from http://info.shiftelearning.com/blog/bid/348188/6Ways-Color-Psychology-Can-Be-Used-to-Design-Effective-eLearning Hemani, S., \& Punekar, R. (n.d.). Visual design: Colour theory. Retrieved from http://www.dsource.in/course/visual-design-colour-theory

Hill, T. R. (2008). Using color to create healing environments. Retrieved from https://ovsco.com/wp-content/uploads/2015/12/Healing_Colors.pdf 
Kane, C. L. (2014). Chromatic algorithms: Synthetic color, computer art, and aesthetics after code. Chicago, IL: University Of Chicago Press

Karr, A. (2013). Color and user experience. Retrieved from http://interactions.acm.org/blog/view/color-and-user-experience

Kopacz, J. (2003). Color in three-dimensional design. New York, NY: McGrawHill Professional

Ludlow, A, \& Wilkins, A. (2009). Case report: Colour as a therapeutic intervention. Journal of Autism and Developmental Disorders, 39(5), 815818. doi: 10.1007/s10803-008-0672-5

Mahnke, F. H. (1996). Color, environment, and human response: An interdisciplinary understanding of color and its use as a beneficial element in the design of the architectural environment. New York, NY: Wiley

O'Connor, Z. (2011). Colour Psychology and colour therapy: Caveat emptor. Color Research \& Application, 36(3), 229-234. doi: 10.1002/col.20597

Wright, A. (n.d.). Psychological properties of colours. Retrieved from http://www.colour-affects.co.uk 